\title{
Trajetórias truncadas, trabalho e futuro: jovens fora de série na escola pública de ensino médio'
}

\author{
Paulo Cesar Rodrigues Carrano" \\ Andreia Cidade Marinholl| \\ Viviane Netto Medeiros de Oliveiralv
}

I- Pesquisa realizada com o apoio do Conselho Nacional de Desenvolvimento Científico e Tecnológico (CNPq) - Bolsa Produtividade em Pesquisa - e Fundação de Apoio à Pesquisa do Estado do Rio de Janeiro.

II- Universidade Federal Fluminense, Niterói, RJ, Brasil.

Contato: pc.carrano@gmail.com

III- Universidade do Estado do Rio de Janeiro, Rio de Janeiro, RJ, Brasil.

Contato: andreiacmari@gmail.com

IV Universidade Federal Fluminense, Niterói, RJ, Brasil.

Contato: vivinettoliver@hotmail.com

\section{Resumo}

0 artigo discute resultados da etapa quantitativa da pesquisa Jovens fora de série: trajetórias truncadas de estudantes do ensino médio na cidade do Rio de Janeiro. A investigação tem como objetivo geral depreender e compreender trajetórias de escolarização e percursos biográficos de jovens estudantes de ensino médio de escolas públicas que se encontram em situação de defasagem escolar. Neste artigo, apresenta-se o perfil que emerge da aplicação do questionário estruturado a um universo de 593 jovens. A amostra exploratória e não probabilística foi distribuída entre 14 escolas localizadas nas zonas sul, centro, oeste e norte da cidade do Rio de Janeiro. Os jovens participantes da pesquisa fazem parte de classes de Educação de Jovens Adultos (EJA) e do programa de correção de fluxo denominado Autonomia. Enfoque especial de análise é dado à combinação entre trabalho, estudo e constituição de projetos de futuro. Verificou-se que o abandono escolar cria mais problemas para o fluxo da escolarização do que as reprovações. Os dados apontam para a existência de uma superposição entre os tempos de trabalho e escola na vida dos jovens. Nesse sentido, ocorre um duplo efeito do trabalho nas trajetórias dos estudantes. Se, por um lado, trabalhar e estudar representam um desafio para a continuidade dos estudos sem truncamentos do fluxo da escolarização, por outro, a experiência de trabalho cria disposições relacionadas com a independência, a conquista da autonomia e o delineamento de projetos de futuro.

\section{Palavras-chave}

Juventude - Escolarização - EJA - Trabalho - Futuro. 


\title{
Truncated trajectories, work and future: youths behind grade in senior high-school'
}

\author{
Paulo Cesar Rodrigues Carrano" \\ Andreia Cidade Marinho"II \\ Viviane Netto Medeiros de Oliveiralv
}

\section{Abstract}

This paper discusses the results of the quantitative step of the research Youths behind grade: truncated trajectories of senior high-school students in the city of Rio de Janeiro. The investigation has the general purpose of learning and comprehending schooling trajectories and biographical paths of young students in senior high-school from public schools who in a grade below of they are expected. Here, we present the profile that emerges from the application of a structured questionnaire to a universe of 593 youths. The sample is exploratory and not probabilistic and was distributed among 14 schools located in the South, Downtown, West and North areas of the city of Rio de Janeiro. Young participants in the study attend classes in the so-called Young and Adult Education (EJA) and in the flow-correcting program named Autonomy. A special focus in the analysis is given to the combination of work, study and the formation of projects for the future. We have found that school drop-out creates more problems for the schooling flow than failure. Data points to the existence of an overlapping between the times of work and school in the life of these young people. Thus, there is a double effect of the work onto the students' trajectories. If, on one hand, working and going to school mean a challenge for the continuation of studies without truncating the schooling flow, on the other hand, the experience of work creates dispositions associated with independence, the achievement of autonomy and the outlining of projects for the future.

I- Pesquisa realizada com o apoio do Conselho Nacional de Desenvolvimento Científico e Tecnológico (CNPq) - Bolsa Produtividade em Pesquisa - e Fundação de Apoio à Pesquisa do Estado do Rio de Janeiro.

II- Universidade Federal Fluminense, Niterói, RJ, Brasil.

Contact: pc.carrano@gmail.com

III- Universidade do Estado do Rio de Janeiro, Rio de Janeiro, RJ, Brasil.

Contact: andreiacmari@gmail.com

IV Universidade Federal Fluminense, Niterói,

RJ, Brasil.

Contact: vivinettoliver@hotmail.com

\section{Keywords}

Youth - Schooling - Youth and Adult Education (EJA) - Work - Future. 
As trajetórias truncadas ou irregulares de escolarização expressam a sonegação de direito básico à cidadania e se constituem como entrave ao desenvolvimento regional e nacional, principalmente se considerarmos os impactos negativos da subescolarização para o desenvolvimento econômico e social de uma região ou país.

É fácil notar os efeitos deletérios da irregularidade das trajetórias escolares no ensino médio. Essa fase da escolarização, além de produzir seus próprios entraves à escolarização, ainda herda o histórico de defasagens idade-série acumulado nos anos anteriores da escolarização.

Em síntese, percebe-se a criação de uma espécie de sistema precário de escolarização que atravessa tanto o ensino fundamental quanto o médio. Este sistema é marcado por processos de escolarização de baixa infraestrutura e insuficiente formação acadêmica que a escola consegue oferecer e na socialização que possibilita. Uma das peculiaridades desse processo é que os jovens, em especial os jovens pobres, vêm sendo os mais atingidos por ele.

Na cidade do Rio de Janeiro, campo de investigação que adotamos na pesquisa, a taxa média de distorção idade-série é de 47\% no ensino médio, sendo a mais alta incidência no primeiro ano (49\%), seguido de taxas menores para os segundos (48\%) e terceiros anos (43\%) (Instituto Nacional de Estudos e Pesquisas Educacionais Anísio Teixeira - INEP/Censo Escolar, 2012).

Observa-se que quanto mais se avança na idade, menor é a taxa de frequência escolar. No Brasil, 24,4\% dos jovens na faixa-etária entre 18 e 24 anos estudam em algum nível de ensino. 0 restante $(75,6 \%)$ encontra-se fora do jogo da escolarização (Instituto Brasileiro de Geografia e Estatística - IBGE/PNAD, 2012). Segundo Castro e Aquino (2008), entre 25 e 29 anos a cifra é ainda maior, sendo $87 \%$ os que estão fora do sistema escolar e muito deles sem a conclusão da escolaridade básica. A título de comparação, nos países que integram a Unidade Europeia a situação é inversa à do Brasil, sendo
13,5\% os indivíduos entre 18 e 24 anos que não frequentavam o ensino nem qualquer outra formação no início de 2012 (EUROSTAT, 2014).

\section{A escolarização como prova}

Martuccelli (2007) assinala que os indivíduos, ao serem obrigados a se defrontar com obstáculos diversos (provas ou desafios), socialmente produzidos e diferencialmente distribuídos, podem ter êxito ou fracassar, tal como ocorre em toda a prova no sentido mais escolar do termo. As provas não são independentes das posições e dos contextos sociais realmente vividos, mas são heterogêneas no interior de uma mesma posição social e dos contextos de vida semelhantes. Sendo múltiplas, explicariam os sentimentos plurais que experimentam os atores uma vez que o que ganham em determinado momento podem perder em outra ocasião.

Em todo caso, muitas das características sociais e individuais (em termos de gênero, de idade, raça/cor, de estado de saúde e de recursos materiais) adquiririam sentido na relação com esses desafios existenciais pelo e no contexto social que rodeia o indivíduo. Assim, o principal problema de investigação não seria o de quantificar os recursos disponíveis para os atores ou mesmo aquilo que lhes falta, mas descobrir, no interior de determinado contexto social, as provas efetivamente vividas. No caso dos jovens fora de série que investigamos, conciliar a dupla condição de estudante e trabalhador é fator decisivo no desafıo da escolarização. Tal desafıo parece ser agravado pela realidade de escolas que aparentam ignorar que expressiva parte de seus alunos também já são trabalhadores ou se encontram em busca de trabalho.

\section{A metodologia com questionários estruturados e o campo de investigação}

Na produção de nossa base de dados, tivemos o cuidado de selecionar 14 escolas 
de ensino médio da rede pública estadual, localizadas em quatro zonas da capital do Rio de Janeiro, para mantermos um critério proporcional entre as unidades de análise de bairro. Conseguimos, assim, uma aproximação com o comportamento de certos segmentos da população de estudantes que estudam na modalidade EJA e no Programa Autonomia, público que o sistema escolar estadual já havia selecionado como sujeitos em defasagem idade-série.

\section{Programa Autonomia é parceria} público-privada entre a Secretaria de Estado de Educação (SEEDUC/RJ) e a Fundação Roberto Marinho. Visa a diminuir a distorção idadesérie dos alunos da educação básica com idade mínima de 15 anos no ensino fundamental e de 17 anos no ensino médio, utilizando a metodologia de videoaulas do denominado programa Telecurso. Os participantes (alunos com dois anos de defasagem idade/série) têm quatro horas diárias de aula em turmas diferenciadas, com o mínimo de 20 e o máximo de 35 alunos, divididos em equipes e orientados pelo mesmo professor, responsável por ministrar todas as disciplinas da grade curricular durante todo o programa.

A amostra deu-se por julgamento, amostra não probabilística, selecionada a partir de critérios pessoais a respeito dos elementos que são mais representativos na população (COSTA NETO, 1977, p. 45). 0 emprego desse tipo de técnica amostral requer reconhecimento prévio da população que será selecionada (MASSUKADO-NAKATANI, 2009). Desta forma, tem-se estudo de caso cujos dados produzidos não permitem generalizações. A pesquisa proporcionou, contudo, fontes significativas para a identificação da dinâmica do perfil dos estudantes jovens denominados fora de série e que podem ser cotejadas com outros contextos de instituições e populações semelhantes.

0 instrumento consistiu de um questionário estruturado, autoaplicável, com questões fechadas e algumas poucas abertas para livre resposta dos entrevistados. Quando foi aplicado, em novembro de 2013, houve o cuidado de informar aos respondentes os objetivos da investigação e que seriam adotados critérios éticos consagrados para a pesquisa científica e que a confidencialidade dos dados estaria assegurada. Dentro do mesmo princípio, evidenciou-se que a resposta ao questionário era voluntária e que o mesmo poderia não ser respondido ou abandonado sempre que o entrevistado assim o desejasse.

A partir da coleta, tabulação e análise do material, foi possível obter uma visão objetiva da situação de escolarização dos estudantes das escolas que constituíram o campo de investigação. 0 questionário foi fonte primária para a seleção e convite de jovens participantes da etapa qualitativa da pesquisa, que busca inventariar trajetórias subjetivas (DUBAR, 1998). 0 espaço e a delimitação deste artigo não permitirão a apresentação e discussão das entrevistas narrativas com jovens que responderam ao questionário e que declararam disponibilidade para a fase subsequente da pesquisa.

Dubar (1998) contrapõe duas perspectivas de análise das trajetórias sociais. A primeira trata a questão como uma sequência de posições em um ou mais campos da prática social (trajetórias objetivas), em contraposição a outras posições que buscam considerá-la como uma história pessoal cujo relato atualiza visões de si e do mundo (trajetórias subjetivas). Para o autor, deve-se considerar em uma perspectiva relacional tanto as posições objetivas (escolares, profissionais) quanto as categorias de linguagem que os sujeitos utilizam para narrar suas histórias de vida em situações de entrevista.

Os dados a seguir permitem a reflexão a respeito de fatores extra e intraescolares intervenientes nas trajetórias escolares desses jovens que apresentam truncamento do fluxo de escolarização. Os resultados da pesquisa revelam condições de existência e trajetórias de escolarização dos referidos jovens e dão pistas a respeito dos modos como vêm sendo desenvolvidas ações e políticas públicas de correção fluxo escolar. 


\section{Síntese de dados}

A pesquisa alcançou um universo de 933 indivíduos, assim distribuídos segundo a faixa de idade: até 18 anos (148), de 19 a 23 anos (343), de 24 a 28 anos (90), de 34 a 38 anos (67), de 39 a 45 anos (102) e acima de 46 anos (97). Neste artigo, são consideradas respostas de 593 indivíduos do corte etário de até 29 anos de idade que se encontravam em situação de defasagem escolar, portanto, matriculados em turmas de EJA (61,6\%) e do programa Autonomia (36,9\%).

A amostra reuniu estudantes matriculados nos três turnos escolares, sendo $74,2 \%$ no noturno, 17,3\% no turno da manhã e 7,4\% matriculados à tarde. Os questionários foram aplicados nas três séries do ensino médio, sendo $17,6 \%$ no primeiro ano, $32,4 \%$ no segundo e $47,1 \%$ no terceiro ano.

No perfil dos jovens que responderam ao questionário foi observado equilíbrio entre os sexos, 51\% são homens e 49\% mulheres. As faixas etárias estão distribuídas entre 15 e 17 anos (1,2\%); 18 a 24 anos $(84,8 \%)$ e 25 a 29 anos (14\%). A maioria se intitula como parda $41 \%$ e preta $20 \%$. Isso significa que mais da metade da amostra é constituída de negros, segundo o padrão classificação do IBGE. Os que se consideram brancos são $26 \%$, os indígenas $3 \%$ e os amarelos 5\%. Ter um universo em que a maioria é formada por pretos e pardos indica um viés socioeconômico. Segundo o IPEA (2003), o salário do homem branco no Brasil é em média $46 \%$ maior que do homem negro. Dos que recebem menos que um salário mínimo, 63\% são negros. Esta é uma diferença que também pode ser explicada pelo nível educacional dos grupos. Esse viés econômico pode explicar a grande quantidade de jovens de nossa amostra que residem em comunidades (Tabela 1) e que tiveram de abandonar os estudos para trabalhar.

Obtivemos significância ${ }^{1}$ na correlação entre alunos que moram em comunidade $\mathrm{e}$

1- Os testes de significância, usando um alpha de 0,05 (intervalo de confiança de 95\%), permitem afirmar que uma variável exerce influência sobre a outra. abandono no ensino fundamental. Com isso, é possível aceitar a hipótese de que, no grupo estudado, morar em comunidade influenciou no abandono. Este é um eixo de análise significativo que se relaciona às desigualdades sociais de acesso aos saberes (AYED, 2012).

A utilização da expressão comunidade no questionário atendeu tão e unicamente 0 objetivo de buscar saber dos entrevistados se eles moravam ou não em áreas periféricas da cidade, tais como morros ou favelas. Temos a clareza de que comunidade é conceito deslizante (DURHAM, 2004), tal o seu uso alargado e grau de imprecisão. Para efeitos da investigação, contudo, a sua utilização no questionário estruturado foi funcional dado o enraizamento do conceito na representação popular.

Tabela 1 - Alunos que residem em comunidade

\begin{tabular}{c|c|cc|c}
\hline & Frequência & Porcentagem & $\begin{array}{c}\text { Porcentagem } \\
\text { acumulativa }\end{array}$ \\
\hline Sim & 319 & 53,8 & 57,4 \\
\hline Não & 237 & 40,0 & 100,0 \\
\hline Total & 556 & 93,8 & \\
\hline Sem informação & 37 & 6,2 & \\
\hline Total & 593 & & 100,0 & \\
\hline
\end{tabular}

Fonte: Pesquisa jovens fora de série - UFF/UNIRIO/UERJ.

A cor no Brasil é considerada uma metáfora da exclusão socioeconômica, um demarcador de desigualdades calcado na raça (ARAÚJO, 1987, p. 5). Um estudo de Heringer (2002), que analisou a ampliação do acesso à escola, concluiu que a proporção de negros com 12 anos ou mais de estudos em 1996 era quase quatro vezes menor que a dos brancos. Estudo mais recente do IPEA (2005) aponta que enquanto mais da metade dos brancos finaliza o ensino médio, apenas 33\% dos negros consegue realizá-lo. Dentre os jovens nascidos em 1980 que em 2003 nunca tinham frequentado uma escola, 1\% era branco e 3\% eram negros.

Nesta pesquisa, dos que vivem com até um salário mínimo tem-se um percentual 
de 24\%, contabilizando também uma média de quatro pessoas por família, ou seja, cada membro vive com $\mathrm{R} \$ 181,00$ per capita ao mês. Esse cenário de debilidade econômica, que se reproduz dentro da própria família, tende a incidir negativamente sobre a disponibilidade de dedicação exclusiva do jovem à vida escolar.

No universo pesquisado, $41 \%$ dos jovens vivem com até dois salários mínimos, numa média de quase quatro pessoas por família vivendo com essa renda. Em uma análise por cor, verifica-se que 25\% dos negros vivem com até um salário mínimo em comparação a 19,4\% dos brancos que recebem a mesma quantia. Dos jovens negros, observamos 68\% com até dois salários, enquanto 56\% dos brancos vivem com a mesma renda. Apesar dos jovens serem, em média, de baixa renda, os negros se encontram em situação econômica inferior. Esse resultado insere o negro em um cenário de maior vulnerabilidade econômica que tende a fragilizar a disponibilidade para a dedicação ao tempo de escola.

Em relação ao atraso escolar, duas variáveis dominam estatísticas em educação: escolaridade dos pais e números de irmãos. Famílias numerosas apresentam maior dificuldade em dar suporte educacional, na medida em que é preciso distribuir recursos e tempo para cada um dos filhos. Isso faz com que o aumento do número médio de irmãos produza o aumento também da média de crianças com atraso escolar (HONDA, 2007). Estar dentro de uma família numerosa também pode influenciar o jovem a entrar no mercado de trabalho cedo, já que a renda não é suficiente para manter todos os integrantes da casa.

A pesquisa obteve informações críticas em relação às diferenças de sexo, idade, trabalho e renda (Tabela 2). Dentre os que nunca trabalharam 13\% são homens e 20\% mulheres. 0 trabalho iniciado em idade inferior aos 10 anos também foi mais acentuado entre os homens (7\%) e menor entre as mulheres (2\%); entre 10 e 15 anos, novamente os homens (26\%) e mulheres com (17\%) apresentaram maior incidência em atividades de trabalho. Entretanto, daqueles que começaram a trabalhar com idade acima dos 18 anos, os resultados apontam para o percentual superior de mulheres com 19\% contra 9\% dos homens.

As mulheres da pesquisa começaram a trabalhar mais tarde e recebem menos. Mais da metade das jovens que trabalham $(61,5 \%)$ recebem até um salário mínimo, já os homens que recebem o mesmo são 39\%. Vale ressaltar que as ocupações são equilibradas entre os sexos - pouco mais da metade em ambos os sexos são trabalhadores prestadores de serviços, vendedores no comércio, em lojas e mercados. A faixa de dois a cinco salários mínimos contempla o sexo masculino com 6,4\% e o feminino com 3,4\%. Entretanto, não se obteve correlação significante entre ter ou não carteira assinada e o sexo correspondente.

Tabela 2 - Relação entre faixa salarial e sexo

\begin{tabular}{|c|c|c|c|}
\hline & \multicolumn{2}{|c|}{ Salário } & \multirow{2}{*}{ Total } \\
\hline & Masculino & Feminino & \\
\hline \multirow{2}{*}{ Até um salário mínimo } & 67 & 72 & 139 \\
\hline & $39,0 \%$ & $61,5 \%$ & $48,1 \%$ \\
\hline \multirow{2}{*}{$\begin{array}{l}\text { De } 1 \text { a } 2 \text { salários } \\
\text { mínimos }\end{array}$} & 93 & 41 & 134 \\
\hline & $54,1 \%$ & $35,0 \%$ & $46,4 \%$ \\
\hline \multirow{2}{*}{$\begin{array}{l}\text { De } 2 \text { a } 5 \text { salários } \\
\text { mínimos }\end{array}$} & 11 & 4 & 15 \\
\hline & $6,4 \%$ & $3,4 \%$ & $5,2 \%$ \\
\hline \multirow{2}{*}{$\begin{array}{l}\text { Mais de } 5 \text { salários } \\
\text { mínimos }\end{array}$} & 1 & 0 & 1 \\
\hline & ,6\% & $0,0 \%$ &, $3 \%$ \\
\hline \multirow[t]{2}{*}{ Total } & 172 & 117 & 289 \\
\hline & $100,0 \%$ & $100,0 \%$ & $100,0 \%$ \\
\hline
\end{tabular}

Fonte: Pesquisa jovens fora de série - UFF/UNIRIO/UERJ.

A natureza das ocupações que exigem pouca escolaridade se associa ao início da atividade produtiva ainda no ensino fundamental de muitos dos jovens participantes da pesquisa. A categoria mais citada $(54,2 \%)$ foi a de trabalhadores de serviços, vendedores de comércio e de lojas, a qual contempla atividades como: garçom, diarista, doméstica, balconista e 
manicure. A classificação das ocupações que os alunos mencionaram (Tabela 3) foi construída a partir do Código Brasileiro de Ocupações do ano de 2002.

Tabela 3 - Ocupações citadas pelos jovens fora de série.

\begin{tabular}{|c|c|c|c|c|}
\hline & Frequência & Percentual & Percentual Válido & Percentual acumulado \\
\hline $\begin{array}{l}\text { Trabalhadores dos serviços, vendedores do comércio em } \\
\text { lojas e mercados }\end{array}$ & 130 & 21,9 & 54,2 & 54,2 \\
\hline Trabalhadores de serviços administrativos & 53 & 8,9 & 22,1 & 76,3 \\
\hline $\begin{array}{c}\text { Trabalhadores da produção de bens e serviços } \\
\text { industriais }\end{array}$ & 36 & 6,1 & 15 & 91,3 \\
\hline Soldados membros das forças armadas & 9 & 1,5 & 3,8 & 95 \\
\hline Trabalhadores em serviços de reparação e manutenção & 7 & 1,2 & 2,9 & 97,9 \\
\hline $\begin{array}{c}\text { Trabalhadores da produção de bens e serviços } \\
\text { industriais }\end{array}$ & 3 & 0,5 & 1,3 & 99,2 \\
\hline Trabalhadores agropecuários, florestais e da pesca & 2 & 0,3 & 0,8 & 100 \\
\hline Total & 240 & 40,5 & 100 & \\
\hline Não Responderam & 353 & 59,5 & & \\
\hline Total & 593 & 100 & & \\
\hline
\end{tabular}

Fonte: Pesquisa jovens fora de série - UFF/UNIRIO/UERJ.

Foram feitos testes de correlação de chi-quadrado, método que serve para avaliar se existe relação entre o resultado do experimento e a distribuição esperada no fenômeno. Com ele, pode-se afırmar se existe correlação entre as variáveis e assim rejeitar a hipótese nula, ou seja, rejeitar que não existe correlação entre os elementos testados. Vale ressaltar que foram usados nos testes um nível de significância convencional, que se expressa por um parâmetro chamado alpha. 0 nível de significância é de 0,05, o que equivale dizer que está se trabalhando com um intervalo de confiança de 95\% no teste de hipótese.

Nos experimentos foi obtida correlação positiva entre abandonar o ensino fundamental e ter trabalhado e estudado. Dos jovens que nunca precisaram trabalhar e estudar, 83\% não abandonaram 0 ensino fundamental. Entretanto, 65\% desses que nunca trabalharam e estudaram repetiram o ensino fundamental e $o$ ensino médio e também já haviam abandonado o ensino médio. Apesar de trabalhar e estudar simultaneamente se constituir em obstáculo na trajetória escolar, no grupo estudado o fenômeno não parece estar associado mais diretamente às reprovações mas, sim, ao abandono. Naquilo que se relaciona com a repetência, outros fatores podem estar envolvidos. Este resultado corrobora os estudos de Cacciamali e Braga (2002) que afirmaram que as motivações envolvidas na defasagem, assim como a evasão, não são causas da entrada dos jovens no mercado de trabalho, mas que podem 
se originar no próprio sistema pedagógico, ou seja, níveis de inadequação idade-série tendem a ser sempre altos, independentemente dos jovens estarem ou não trabalhando.

Se, por um lado, não é o trabalho a maior influência para a relação inadequada entre idade e série de escolarização, a pobreza, por sua vez, pode ter forte impacto no desempenho escolar.

Andrews e Vries (2012) estudaram 5.500 municípios brasileiros, onde a pobreza foi a variável explicativa da defasagem e a evasão com uma amplitude que esclarece $60 \%$ da variação. A tese de que a pobreza só pode ser superada por meio da educação escolar (EASTERLIN, 1981; HANUSHEK, 1995) é relativizada pelas evidências de que não é possível melhorar a educação sem a superação da pobreza (ANDREWS; VRIES, 2012, p. 844). É neste contexto que se afirma que as desigualdades econômicas delimitam horizontes possíveis de ação dos jovens em suas relações com a escola e o mundo do trabalho (SPOSITO, 2005).

Dos entrevistados que declararam trabalhar e estudar em algum momento de suas trajetórias escolares, 30\% abandonaram a escola no ensino fundamental. Uma proporção sensível da amostra diz respeito à idade dos que começaram a trabalhar. 4,9\% dizem ter começado a trabalhar com menos de 10 anos, $21 \%$ entre 10 e 15 anos e $41 \%$ entre 16 e 18 anos. Tais dados permitem pensar acerca dos entraves, ainda grandes, para a erradicação do trabalho infantil e a proteção do trabalho de adolescentes no Brasil, de forma que o mesmo não se constitua num obstáculo à escolarização.

Sabemos que a posição social dos pais e seus níveis de escolaridade estabelecem fortes correlações com a escolaridade dos filhos, em especial, pelos suportes materiais e financeiros necessários para a formação quanto pelas possibilidades que se abrem para o acompanhamento da vida escolar dos filhos. Barbosa (2009) ressalta, contudo, que estudos, notadamente no campo da psicologia, permitiram constituir instrumentos capazes de medir o clima familiar de forma a avaliar o impacto de diferentes tipos de autoridade paterna, da perspectiva familiar a respeito da prioridade do senso de dever, ou do sentido de realização pessoal sobre o desempenho escolar. É nesse sentido que a influência das famílias no desempenho escolar dos filhos não pode ser considerada como puro reflexo de uma condição material, econômica ou de estágio de mobilidade escolar. As análises necessitam combinar as dimensões do material-objetivo e do simbólico-cultural.

Forquin (1995), em suas pesquisas a respeito da desigualdade e do sucesso escolar, alertava que as oportunidades de prosseguir os estudos dependiam mais da origem social do que aquilo que chamou de talento:

- o fracasso escolar [...] atinge de forma muito mais maciça e regular as crianças dos meios populares; ora, essa verdade estatística pode ser também um motivo de escândalo. (FORQUIN, 1995, p. 81).

Esta oportunidade de prosseguir os estudos, segundo o autor, varia dentro da origem social até quando o sucesso obtido é equivalente. Considerando a distinção social, o status dos pais tem mais força que o nível de remuneração. É nesse sentido que se deve problematizar a questão, uma vez que a renda não é fator explicativo de todos os casos, ainda que se constitua em variável forte que irá compor a formação cultural dos pais.

Estudantes que repetiram três ou mais vezes, num total de 52\%, são filhos de mães sem escolaridade ou somente com fundamental incompleto. Ao passo que 55\% dos que nunca repetiram também têm mãe com escolaridade baixa, 13,4\% sem escolaridade e 41,6\% com ensino fundamental incompleto. Apesar das pesquisas em educação apontarem para grande influência da escolaridade da mãe no desempenho escolar, a amostra obteve resultados percentuais bem distribuídos nas categorias estudadas. 
A partir do teste de correlação realizado, afırma-se que existe relação entre ter trabalhado e estudado e o abandono do ensino fundamental. No ensino fundamental, dos alunos que já trabalharam e estudaram, 65,4\% nunca abandonaram os estudos (Tabela 4), enquanto que $78,2 \%$ dos que não trabalharam também nunca abandonaram. Com frequência parecida, $65,5 \%$ dos que trabalharam e estudaram reprovaram uma ou mais vezes no ensino fundamental.

A diferença é suave, mas aqueles que nunca trabalharam abandonaram menos a escola no primeiro segmento. 0 trabalho foi motivo declarado para abandono no ensino fundamental para 43\% dos homens e 19\% das mulheres.

Tabela 4 - Alunos que abandonaram a escola no ensino fundamental segundo a combinação trabalho e estudo

\begin{tabular}{|c|c|c|c|}
\hline \multirow[b]{2}{*}{ Abandonou } & \multicolumn{3}{|c|}{ Já trabalhou e estudou? } \\
\hline & $\operatorname{sim}$ & não & Total \\
\hline \multirow[t]{2}{*}{ Nunca } & 282 & 97 & 379 \\
\hline & $65,4 \%$ & $78,2 \%$ & $68,3 \%$ \\
\hline \multirow[t]{2}{*}{ Uma vez } & 100 & 15 & 115 \\
\hline & $23,2 \%$ & $12,1 \%$ & $20,7 \%$ \\
\hline \multirow[t]{2}{*}{ Duas vezes } & 16 & 4 & 20 \\
\hline & $3,7 \%$ & $3,2 \%$ & $3,6 \%$ \\
\hline \multirow[t]{2}{*}{ Três ou mais } & 14 & 1 & 15 \\
\hline & $3,2 \%$ & $0,8 \%$ & $2,7 \%$ \\
\hline \multirow[t]{2}{*}{ Sem informação } & 19 & 7 & 26 \\
\hline & $4,4 \%$ & $5,6 \%$ & $4,7 \%$ \\
\hline \multirow[t]{2}{*}{ Total } & 431 & 124 & 555 \\
\hline & $100 \%$ & $100 \%$ & $100 \%$ \\
\hline
\end{tabular}

Fonte: Pesquisa jovens fora de série - UFF/UNIRIO/UERJ.
No ensino médio, apesar do teste de correlação não ter sido significativo, o impacto de ter trabalhado e estudado sobre a categoria abandono foi emblemático. Dos que já trabalharam e estudaram, 58,1\% nunca abandonaram os estudos; para aqueles que nunca trabalharam, $74,6 \%$ nunca abandonaram. 0 percentual de quem trabalha e estuda é relativamente proporcional na repetência e em relação aos que não trabalham. Não foi encontrado resultado positivo de correlação entre trabalhar e repetir alguma série do ensino médio, sendo $56 \%$ o percentual dos que nunca repetiram e trabalham e $11 \%$ os que nunca repetiram e só estudam sem trabalhar. Mais da metade dos jovens que nunca repetiram estão no mercado de trabalho.

Entretanto, para o abandono há diferenças. Aqueles que trabalham e estudam têm mais dificuldade de permanecer na escola. Indagados a respeito dos motivos do abandono, o significativo número de $34,7 \%$ apontou o trabalho como o principal responsável.

Na ocasião da aplicação do questionário, $11,4 \%$ declararam somente estudar. Em contrapartida, a grande maioria das respostas esteve relacionada com o mundo do trabalho, sendo que $17,8 \%$ informaram estar procurando emprego; 43,1\% que possuem emprego fixo; $10,4 \%$ que fazem biscate e 1,7\% que se ocupam de afazeres domésticos (Tabela 5). Daqueles que trabalham, 47\% são remunerados e 11,1\% declararam nada receber pelo trabalho. A carteira de trabalho é assinada para $35,1 \%$; os que responderam que trabalham sem carteira são $27,2 \%$. A faixa salarial de até um salário mínimo é recebida por $23,3 \%$, enquanto $22,7 \%$ recebem de 1 a 2 salários; 2,5\% recebem entre dois e cinco salários mínimos mensais e somente um $0,2 \%$ tem ganhos superiores a cinco salários. 
Tabela 5 - Situação frente ao trabalho

\begin{tabular}{|c|c|c|c|}
\hline & Frequência & Porcentagem & Porcentagem acumulativa \\
\hline Não, só estudo & 68 & 11,5 & 13,6 \\
\hline Não, mas procuro emprego & 106 & 17,9 & 34,8 \\
\hline Sim, tenho trabalho fixo & 256 & 43,2 & 86 \\
\hline Sim, faço biscates & 62 & 10,5 & 98,4 \\
\hline Sim, ajudo nos afazeres domésticos & 8 & 1,3 & 100 \\
\hline Total & 500 & 84,3 & \\
\hline Sem informação & 93 & 15,7 & \\
\hline Total & 593 & 100 & \\
\hline
\end{tabular}

Fonte: Pesquisa jovens fora de série - UFF/UNIRIO/UERJ

Considerando a carga horária diária de trabalho, número majoritário $(22,5 \%)$ trabalha entre seis e 8 horas; seguidos de 15,8\% que trabalham mais de 8 horas, 9,4\% (de 4 a 6 horas), 4,4\% (de 2 a 4 horas) e 2,2\% (até duas horas). Os principais turnos de trabalho estão na parte da manhã $(21,6 \%)$, em seguida vem o período da tarde $(8,4 \%)$ e da noite $(4,7 \%)$; são poucos (4\%) os que trabalham em período integral ou trabalham no período da tarde e noite $(1 \%)$.

Trabalham sem carteira assinada 27,2\% ou fazem biscates 10,5\% dos entrevistados. Esta frequência evidencia o problema do trabalho informal, do subemprego e das ocupações precárias aos quais os jovens com pouca qualificação estão submetidos. É possível intuir que os 17,9\% que declararam estar em busca de trabalho sejam fortes candidatos a entrada nesta categoria de trabalhadores desprotegidos. Pesquisa realizada por Raitz, (2008) que investigou jovens do ensino médio noturno no interior de Santa Catarina, obteve um resultado similar: com 22\% de jovens ocupados em trabalhos formais e 39\% que se encontravam em situação de informalidade.

Ao se verificar a situação dos jovens no mercado de trabalho no Brasil, verifica-se que a maior parte deles tem carteira assinada $(56,3 \%)$, embora se note que seja significativo o número dos que vivem na informalidade (43,7\%). Essa superação dos trabalhos formais sobre os não formais reflete uma realidade que vem sendo experimentada pela população brasileira de um modo geral nos últimos anos, conforme apontado na síntese dos indicadores sociais de 2013 (IBGE/SIS, 2013).

Ressalta-se que não possuir carteira assinada não é suficiente para caracterizar o trabalho como informal, entretanto, todo trabalho informal é ausente de registro.

De acordo com estudos do IPEA (2003), a população jovem brasileira tem enfrentado menos barreiras para se inserir no mercado de trabalho formal atualmente. Entretanto, embora entre esse grupo os trabalhos sejam relativamente mais fáceis de se obter hoje do que há uma década, são esses também os mais arriscados de se perder. Os trabalhadores jovens enfrentam altas taxas de rotatividade no Brasil devido tanto a taxas mais elevadas de contratação como também de demissão. Os desligamentos voluntários e os que acontecem em razão do fim dos contratos são também mais frequentes para os trabalhadores jovens.

Nos experimentos com a variável de abandono no ensino médio obteve-se como fortes preditores a variável: ter filhos e ter trabalhado. Em abandono no ensino médio os números apontam significância estatística 
apenas para a variável ter filhos. Na amostra, homens e mulheres abandonam o ensino fundamental e médio na mesma proporção, todavia, homens apresentaram mais chances de reprovação em ambos segmentos.

A pesquisa procurou saber dos jovens o que dificulta ou dificultou o prosseguimento dos estudos. Novamente é a difícil conciliação entre trabalho e estudo que emerge nas respostas. Em ordem de importância, trabalhar e estudar aparece em primeiro lugar com 43\% das respostas; em segundo lugar se encontra o entender o que está sendo ensinado $(17,6 \%)$ seguido de outros fatores relacionados com a precariedade dos suportes à escolarização, tais como a falta de apoio da família $(6,3 \%)$, falta de transporte $(5,1 \%)$ e falta de estrutura da escola $(4,7 \%)$.

Procurou-se saber dos estudantes quais as condições que, na avaliação deles, a escola deveria oferecer a quem trabalha e estuda. As respostas principais estiveram relacionadas com a perspectiva da constituição do que se pode chamar de uma escola mais compreensiva com os trabalhadores-estudantes. Neste sentido, as principais respostas foram o estabelecimento de horário flexível e programa de recuperação de notas. Indagou-se aos que já estudaram e trabalharam o que pretendiam fazer ao concluir o ensino médio. As respostas revelaram equilíbrio entre os que desejam prestar vestibular ou o Exame Nacional do Ensino Médio (ENEM) e fazer ensino superior $(31,4 \%)$ e os que pretendem fazer curso profissionalizante e se preparar para o trabalho $(27,5 \%)$.

Perspectivas de futuro: trabalho e abandono escolar

Quanto às perspectivas desses jovens diante do futuro, os dados apontam um forte desejo de ampliação da escolaridade. Analisando as opções escolhidas pelos jovens na questão: " 0 que você pretende fazer ao concluir o ensino médio?", destaca-se a intenção de busca da continuidade ou de complemento dos estudos para além do ensino médio, seja por meio do ingresso na universidade (43,3\%), ou pela realização de algum curso profissionalizante (26\%). A respeito dos que não expressaram desejo de continuidade dos estudos, 11,2\% pretendem procurar emprego e 3,4\% planejam trabalhar por conta própria ou em negócios da família. A parcela dos que ainda não decidiram o que fazer soma $8,4 \%$ e os que têm outro plano, não especificado no questionário, totalizaram 7,8\%.

As perspectivas de futuro também podem ser observadas num arco temporal um pouco mais extenso a partir das respostas dadas à questão: "O que você pretende fazer em médio prazo?”. Como na questão anterior, as opções de "ter diploma universitário" (24,5\%) e "fazer curso profissionalizante” (18,6\%) assumem posição dominante, confirmando a pertinência de tais perspectivas na vida dos jovens pesquisados. Entretanto, essas perspectivas agora disputam com o desejo de prestar um concurso público $(18,0 \%)$. A procura de um cargo público assim como a busca por carreiras militares $(8,8 \%)$ ou simplesmente a busca por qualquer emprego fixo $(11,8 \%)$ representam um desejo de estabilidade. A opção de "ganhar dinheiro com o próprio negócio" torna-se um pouco mais expressiva nas perspectivas em médio prazo, representando agora 11,6\% das respostas. Entre os jovens que revelaram ainda não ter decidido ou planejado o que fazer, seja a curto $(8,4 \%)$ ou em médio prazo $(5,1 \%)$, pode-se supor uma postura de maior incerteza frente ao futuro.

Boa parte dos jovens viveu experiências de abandono da escolarização em algum ponto de sua trajetória escolar, sendo este um dos principais fatores da distorção idade-série. É interesse analisar, neste momento, o que esses sucessivos abandonos e reingressos revelam a respeito das expectativas desses jovens diante do futuro.

As trajetórias escolares de boa parte dos jovens da pesquisa apresentam percursos intermitentes de idas e vindas à escola em diferentes momentos da vida. Entretanto, diferente do que acontece com as ocorrências de repetência, que se situam majoritariamente 
no ensino fundamental, os casos de abandono são mais insistentes no ensino médio. Enquanto $35,2 \%$ dos jovens investigados abandonou o ensino fundamental, 44,6\% declarou ter abandonado o ensino médio em alguma ocasião. Os motivos que levaram esses jovens a abandonar a escola também variam em ordem de importância de um segmento para o outro.

No ensino fundamental, grande parte dos alunos abandonou depois de já ter faltado muito e, possivelmente, por perceber a iminência da reprovação. Destaca-se ainda como motivadores do abandono o "não entendimento das matérias" ensinadas e o "não gosto pelos estudos". Já no ensino médio, as dificuldades decorrentes de conciliar trabalho e estudo foram apontadas como fator que motivou a maior parte das evasões, vindo em seguida o fato de terem tido filhos.

Considerando a relação entre trabalho e abandono, os jovens que declararam trabalhar e estudar são de fato aqueles que apresentam maior probabilidade de abandonar tanto no ensino fundamental como no ensino médio. Entretanto, o impacto de ter trabalhado é ainda mais determinante neste último nível de ensino.

Ao se correlacionar planos de futuro com abandonos no ensino fundamental, percebe-se que os jovens que mais interromperam os estudos nesta etapa de ensino são aqueles que apresentaram menores expectativas de ingressar no nível superior. Observa-se que, quanto mais crescem os números de abandonos, crescem também as perspectivas de buscar cursos profissionalizantes com o término do ensino médio.

Quando se cruzam planos de futuro com abandonos no ensino médio, curiosamente se obtém resultados inversos ao observado no nível fundamental. Os jovens que mais abandonaram a escola no nível médio de ensino são os que têm mais expectativas de elevar sua escolarização ingressando numa universidade.

Como compreender esse aparente paradoxo? Como entender que jovens que mais abandonam são os que nutrem mais expectativas diante do prosseguimento da escolarização? Uma saída interpretativa está em não focar o olhar simplesmente no abandono, mas no sentido que o retorno escolar assume na vida dos jovens. Enquanto que para alguns o prolongamento da escolaridade não se constitui, necessariamente, em projeto de vida, para vários o retorno à escola é uma meta carregada de significado positivo que alinhava sonhos e reconfigurações de planos de futuro.

Investigando os sentidos do retorno à escola na vida de jovens da EJA, Carrano e Costa (2011) salientam que o reingresso se identifica com a aposta de reconfigurar projetos de vida e sonhos adiados por circunstâncias adversas. A retomada da escolarização ganha um novo sentido para aqueles que a estão experimentando pela segunda, terceira ou mais vezes. Assim, pode-se dizer que o retorno se relaciona com os sentidos que os jovens atribuem ao seu processo de escolarização e que estão relacionados a projeções futuras e reformulações de projetos de vida. Em virtude disto, a educação de jovens e adultos deveria ser vista não como um local de continuidade para uma mera certificação, embora se reconheça a importância desta função. Mas, concebida como escola do recomeço, um lugar que auxilie os jovens nessa reconfiguração de projetos, fornecendo os suportes necessários para a superação das provas diárias que se impõem na vida daquele que decide pela retomada dos bancos escolares.

0 retorno à escolarização parece representar para os jovens da EJA, e em especial para os jovens adultos, um momento singular de retomada dos sentidos da escola, os quais se alimentam de sonhos e projeções futuras. As experiências vividas em outros espaços e momentos possibilitam a esses jovens compreender a importância da escola, de seus códigos e linguagens, para melhor se situarem na sociedade.

É possivel que quando muitos desses jovens passam a vivenciar os entraves provocados pala ausência de credenciais escolares, seja no mercado de trabalho ou 
na vida social, a interrupção dos estudos seja revista e o reingresso passe a ser uma alternativa. Assim, redescobre-se a escola como um caminho indispensável para uma melhor colocação nos contextos sociais em que vivem.

Duschatkky (1999 apud ZAG0 et al., 2000, p. 28) afırma que "a escola adquire sentido para os sujeitos quando a experiência escolar entra no horizonte de suas expectativas de vida". Assim, é especialmente nesse momento que o estudo ganha real significado instrumental, constituindo-se como peça chave na retomada dos projetos de vida, muitas vezes, após vários anos de interrupção da trajetória escolar.

Quais seriam, então, os impactos do trabalho nas expectativas de futuro desses jovens? A combinação do estudo com a atividade laboral seria um fator necessariamente contraditório na construção dos projetos de vida?

A experiência no mundo do trabalho, com todos os riscos e incertezas nele contidos, é uma realidade conhecida pela maior parte dos jovens no país e não diferente para os jovens desta pesquisa. Para 78,6\% deles, vivenciar tal experiência conciliando com os estudos é (ou já foi) uma realidade cotidiana.

Não se pode negar o impacto de tal condição na trajetória do grupo em questão, já que o trabalho foi apontado por 34,7\% deles como um dos principais responsáveis pelo abandono no ensino médio, como já vimos anteriormente. Ao se correlacionar trabalho e estudo com os percentuais de abandonos nesse nível de ensino, observou-se que ter trabalhado e estudado parece ter influenciado no abandono da escola, já que dos que já trabalharam e estudaram 42,9\% abandonou os estudos, enquanto que entre aqueles que nunca trabalharam 25,4\% abandonou.

Esses dados reforçam o quanto a articulação entre os estudos e o trabalho continua a ser uma tarefa difícil de ser realizada. Entretanto, os significados de tal relação na experiência dos jovens precisam ser problematizados. Afınal, seria essa simultaneidade entre escola e trabalho a grande rival dos projetos de vida dos jovens? É interessante observar que parte significativa dos sujeitos investigados vê essa conciliação não necessariamente como algo negativo, mas como uma situação até desejável. Ao serem indagados a respeito de como avaliavam ter estudado e trabalhado, 24,2\% consideraram que tal experiência não atrapalhou os estudos, 17,3\% disseram que essa conciliação lhes possibilitou crescimento pessoal e 2,3\% responderam que só conseguiram retornar aos estudos porque estavam trabalhando.

Ao se correlacionar trabalho e estudo com expectativas de futuro notam-se, curiosamente, influências favoráveis dessa simultaneidade nos projetos de vida dos jovens investigados. Percebe-se que os que já conciliaram o tempo de escola com o mundo do trabalho chegam a ter maiores expectativas de ampliar sua formação, seja obtendo em médio prazo um diploma universitário ou mesmo fazendo um curso profissionalizante. As expectativas desse grupo de galgar empregos públicos também são maiores. Na parcela dos que nunca conciliaram trabalho e estudo, percebe-se um percentual maior daqueles que desejam tão somente buscar um emprego fixo e dos que almejam ganhar dinheiro com o próprio negócio. Esse também é o grupo que reúne a maior parcela daqueles que nada planejaram para o futuro na ocasião da pesquisa.

Não se pode dizer que a conciliação do estudo com o trabalho tenha sido um fator negativo na construção dos planos de vida dos jovens investigados. Para muitos, essa simultaneidade lhes abriu campos de possibilidades para a ampliação dos horizontes de futuro, o que pode ter contribuído para renovar os sentidos da presença na escola. É possivel que as experiências adquiridas nas relações de trabalho tenham colaborado para demonstrar a importância da ampliação das credenciais escolares na busca de ascensão econômica e social.

Para esses jovens, trabalho e escola não são projetos que se excluem, mas, assim 
como já foi observado por Sposito (2008), são projetos que se superpõem. Pode-se dizer que ambos jogam papel decisivo na construção das expectativas de futuro dos jovens. Em uma relação de complementaridade, escola e trabalho se articulam para produzir expectativas de futuro e tornar viáveis projetos de vida.

\section{Conclusão}

A elaboração de um projeto de vida é um exercício complexo e condicionado por diversos fatores dispostos no campo de possibilidades dos indivíduos. Os dados da pesquisa permitiram analisar em que medida as expectativas de futuro dos jovens podem ser afetadas por aspectos do perfil socioeconômico e por acontecimentos da trajetória escolar. Nesta investigação, ora os dados apontavam para questões mais previsíveis, que há algum tempo já vêm sendo demonstradas por outras pesquisas, ora levantavam questões menos esperadas, ligadas em grande medida ao contexto de mudança social e aumento de expectativas de mobilidade escolar e social vivenciado atualmente no país.

Ao se investigar os impactos da trajetória escolar na formação de expectativas de futuro, verificou-se o quanto a repetência joga um papel negativo no processo de escolarização. Quanto mais se acumulam anos de retenção, mais diminuem as expectativas de ingresso numa universidade e aumentam as perspectivas de tão somente procurar um emprego ao fım do ensino médio. Foi possível perceber o quanto repetência e autoconceito escolar estão imbricados no conjunto de expectativas de futuro dos jovens.

No que se refere ao abandono, verificou-se que jovens do ensino médio que já abandonaram os estudos revelaram expectativas mais alargadas de ingresso no ensino superior se comparados com os que nunca abandonaram a escola. Estes, em especial, são dados que contribuem para a reflexão acerca da ressignificação da escola em outra fase da vida. Em especial para jovens da EJA, retornar a escola se faz em meio a reconfiguração de projetos de vida na qual a instituição escolar pode assumir relevância.

Resultados semelhantes foram encontrados em relação ao trabalho. Jovens com experiência no mundo laboral apresentaram maiores perspectivas de ingressar no ensino superior demonstrando o quanto trabalho e escola podem se articular para a elaboração de projetos de vida.

Estar fora da série adequada acarreta prejuízos na qualidade da aprendizagem e, em especial, coloca o estudante num lugar simbólico desprestigiado no interior da instituição escolar. As políticas de correção de fluxo escolar se generalizaram por todo o país e, em grande medida, aparentam dar respostas à intencionalidade política de homogeneizar trajetórias de matrículas no ensino regular. Até que ponto este apartamento entre regulares e os fora de série não estaria sonegando direitos à escolarização de qualidade dos que, por diferentes motivos intra e extraescolares, constituíram trajetórias truncadas de escolarização?

Os sistemas de ensino têm respondido à demanda desse público com lugares de muito pouco prestígio e investimento público na instituição escolar - como a EJA ainda é tratada. A cada dia surgem projetos especiais nas diferentes redes de ensino buscando formas de aceleração da aprendizagem ou correção de fluxo afastando jovens das ofertas regulares de escolarização.

Essa descontinuidade dos estudos ainda é pouco estudada. Se, por um lado, é significativo o reingresso na escola pela via do ensino médio, por outro, preocupam as baixas taxas de conclusão. Para cada dois alunos que entram no ensino médio, somente um conclui este nível de ensino.

Existe um aparente paradoxo presente na melhoria das condições socioeconômicas e a persistência do trabalho entre os jovens e, em especial, os adolescentes. 0 trabalho estaria representando não apenas meio de subsistência, 
a necessidade que empurra adolescentes para os mercados laborais seria constituída também por outras mediações, tais como a busca de independência e autonomia dos jovens, o valor atribuído pelas famílias ao trabalho como elemento educativo na formação dos filhos e também como meio disciplinador do caráter e controle da ociosidade juvenil em meios populares. Essas são pistas, então, para o aprofundamento das questões em novos e necessários estudos. É possível dizer que este público escolar constituído por sujeitos jovens e jovens adultos que retornam à escola, ou que nela permanece amargando reprovações sucessivas, ainda é pouco conhecido.

\section{Referências}

ANDREWS, Christina W; VRIES, Michiel S. de. Pobreza e municipalização da educação: análise dos resultados do IDEB (20052009). Cadernos de Pesquisa, São Paulo, v. 42 n. 147, p. 826-847, set./dez. 2012.

ARAÚJO, Tereza Cristina N. A classificação de "cor" nas pesquisas do IBGE: notas para uma discussão. Cadernos de Pesquisa, São Paulo, n. 63, p. 14-15, nov. 1987.

AYED, Choukri Ben. As desigualdades socioespaciais aos saberes: uma perspectiva de renovação da sociologia. Educação e Sociedade, Campinas, v. 33, n. 120, p. 783-803, jul./set. 2012.

BARBOSA, Maria Ligia de Oliveira. Desigualdade e desempenho: uma introdução à sociologia da escola brasileira. Belo Horizonte: Argvmentvm, 2009.

CACCIAMLI, Maria Cristina; Braga, Thaís. Educação e trabalho da população jovem: diagnóstico e políticas. São Paulo: Ministério do Trabalho e Emprego, 2002. p. 11-15.

CASTRO, Jorge Abrahão; AQUINO, Luseni. Juventude e políticas sociais no Brasil. Brasília, DF: IPEA, 2008.

CARRANO, Paulo César; COSTA, Mariane Brito da. Animar sentidos de presença de jovens na escola do recomeço. In: ROSA, Malena Carvalho (Org.). Educação física escolar na educação de jovens e adultos. Curitiba: CRV, 2011. p. 71-82.

COSTA NETO, Pedro Luiz de Oliveira. Estatística. São Paulo: Edgard Blücher, 1977. 264 p.

DUBAR, Claude. Trajetórias sociais e formas identitárias: alguns esclarecimentos conceituais e metodológicos. Educação e Sociedade, Campinas, v. 19, n. 62, p. 13-30, abr. 1998.

DURHAM, Eunice. A dinâmica da cultura. São Paulo: Cosac \& Naify, 2004.

EASTERLIN, Richard A. Why isn't the whole world developed? The Journal of Economic History, v. 41, n. 1, p. 1-19, 1981.

EUROSTAT. Estatísticas da educação a nível regional. [S. I.]: Comissão Europeia. Disponível em: <http://epp.eurostat.ec.europa. eu/statistics_explained/index.php/Education_statistics_at_regional_level/pt\#Aprendizagem_ao_longo_da_vida>.Acesso em: 22 nov. 2014.

FORQUIN, Jean C. Abordagem sociológica do sucesso e do fracasso escolares: desigualdades de sucesso escolar e origem social. In: FORQUIN, Jean C. Sociologia da educação: dez anos de pesquisa. Petrópolis: Vozes, 1995. p. 79-144.

HANUSHEK, Eric A. Interpreting recent research on schooling in developing countries. The World Bank Research Observer, v. 10, n. 2, p. 227-246, aug. 1995.

HERINGER, Rosana. Desigualdades raciais no Brasil: síntese de indicadores e desafios no campo das políticas públicas. Cadernos de Saúde Pública, Rio de Janeiro, v. 18, suppl. p. S57-S65, 2002. Disponível em: <http://www.scielo.br/pdf/csp/v18s0/13793. pdf>. Acesso em: 14 set. 2014.

HONDA, Kátia Morinaga. Um estudo sobre determinantes do atraso escolar. 2007. Dissertação (Mestrado em Educação) Faculdade de Educação da Universidade de São Paulo - FE/USP, São Paulo, 2007. 
INSTITUTO BRASILEIRO DE GEOGRAFIA E ESTATISTICA (IBGE). PNAD: Pesquisa Nacional por Amostra de Domicílios. Brasília, DF: Diretoria de Pesquisas, Coordenação de Trabalho e Rendimento, 2012.

INSTITUTO NACIONAL DE ESTUDOS E PESQUISAS EDUCACIONAIS ANÍSIO TEIXEIRA (INEP). Censo da educação básica: 2012: resumo técnico. Brasília, DF: INEP, 2013.

INSTITUTO DE PESQUISA ECONOMICA APLICADA (IPEA). 0s mecanismos de discriminação racial nas escolas brasileiras. Brasília: IPEA, 2005.

INSTITUTO DE PESQUISA ECONOMICA APLICADA (IPEA). Retrato das desigualdades de gênero e raça: Programa lgualdade de Raça. Brasília, DF: IPEA, 2003.

MARTUCCELLI, Danilo. Cambio de rumbo: la sociedad a escala del individuo. Santiago: LOM, 2007.

MASSUKADO-NAKATANI, Marcia Shizue. Métodos e técnicas de pesquisa em turismo: amostragem. 2009. Disponível em: <http://www.turismo.ufpr.br/drupal5/files/Aula\%2022\%20-\%20Amostragem.pdf>. Acesso em: 20 maio 2012.

RAITZ, Tânia Regina; PETTERS, Luciane Carmem Figueredo. Novos desafios dos jovens na atualidade: trabalho, educação e família. Psicologia \& Sociedade, Belo Horizonte, v. 20, n. 3, p. 408-416, 2008. Disponível em: http://www.scielo.br/scielo. php?script=sci_arttext\&pid=S0102-71822008000300011. Acesso em: 15 set. 2014.

SPOSITO, Marilia. Algumas reflexões e muitas indagações sobre as relações entre juventude e escola no Brasil. In: ABRAMO, Helena Wendel; BRANCO, Pedro Paulo Martoni (Orgs.). Retratos da juventude brasileira: análises de uma pesquisa nacional. São Paulo: Fundação Perseu Abramo, 2005. p. 87-128.

SPOSITO, Marilia; SOUZA, Raquel. Desafios da reflexão sociológica para análise do ensino médio no Brasil. In: NORA KRAWCYZK (Org.). Sociologia do ensino médio: crítica ao economicismo na política educacional. São Paulo: Cortez, 2014. p. 33-62.

ZAGO, Nadir. Processos de escolarização nos meios populares: as contradições da obrigatoriedade escolar. In: NOGUEIRA, Marialice; ROMANELLI, Geraldo; ZAGO, Nadir (Orgs.). Família e escola: trajetórias de escolarização em camadas médias e populares. Petrópolis: Vozes, 2000. p. 19-43

Recebido em: 30.11.2014

Aprovado em: 24.03.2015

Paulo Cesar Rodrigues Carrano é professor associado 1 da Faculdade de Educação e do Programa de Pós-Graduação em Educação da Universidade Federal Fluminense. Bolsista produtividade do CNPq - Nível 2. É doutor em educação (UFF) e coordenador do grupo de pesquisa Observatório Jovem do Rio de Janeiro/UFF, é autor de artigos sobre jovens e ensino médio, organizou o livro Narrativas juvenis e espaços públicos (EDUFF/FAPERJ, 2014), é autor dos livros Juventudes e cidades educadoras (Vozes, 2003) e Os jovens e a cidade (Relume Dumará, 2002).

Andreia Cidade Marinho é cientista social, possui mestrado em sociologia no Instituto de Estudos Sociais e Políticos (IESP/ UERJ, 2012). Cursa 0 segundo ano de doutorado em sociologia no IESP/UERJ. Possui experiência em técnicas de pesquisas quantitativas. É colaboradora de pesquisa no Observatório Jovem do Rio de Janeiro/UFF, e membro integrante da pesquisa na nacional de suicídio em idosos de ILPIs (ENSP-FioCruz).

Viviane Netto de Oliveira é mestre em educação pela Universidade Federal Fluminense (2015). Possui especialização em ensino de história e de ciências sociais pela mesma universidade. Integra o grupo de pesquisa Observatório Jovem do Rio de Janeiro/UFF,. É graduada em história pela Universidade do Estado do Rio de Janeiro (2006). É professora de história da rede pública estadual do Rio de Janeiro. 